\title{
Signo de las líneas de cebra
}

\section{Zebra Lines Sign}

\author{
Juana María Ross ${ }^{1}$ Emanuel Allegretti Pérez ${ }^{1} \quad$ Cintia Climente $^{1}$
}

\author{
1 Servicio de Diagnóstico por imágenes, Imágenes MDQ, Mar del \\ Plata, Argentina
}

Rev Argent Radiol 2021;85:52-54.

El signo radiológico de las líneas de cebra, se refiere a la aparición de bandas lineales de alta densidad ubicadas en la zona metafisaria de los huesos, paralelas al cartílago de crecimiento, que pueden evidenciarse en el estudio radiológico de los miembros (-Figura $\mathbf{1}$ ). Corresponden al reflejo del efecto de los bifosfonatos en el esqueleto en crecimiento y fue descrito en 2007 por Al Muderis y col. ${ }^{1}$

El tratamiento con bisofosfonatos es utilizado en pediatría para el manejo de entidades patológicas con baja densidad mineral ósea y consecuente aumento de la fragilidad de los huesos. La terapia reduce la frecuencia de fracturas y la deformidad ósea posterior, disminuyendo el dolor y mejorando la movilidad de esos pacientes, en beneficio de su calidad de vida. Tal es el caso de pacientes con osteogénesis imperfecta, síndromes de malabsorción, asma dependiente de corticoides y trastornos neuromusculares. ${ }^{1,2}$

La acción de los bifofonatos radica en inactivar e inducir la apoptosis de osteoclastos, disminuyendo asimismo su reclutamiento y diferenciación. ${ }^{1}$ Cuando se administra el medicamento en el esqueleto inmaduro, se forma hueso denso en las metáfisis, que posteriormente con el crecimiento del hueso, se desplazará a la zona diafisaria. El proceso se repite mientras continúen los ciclos de tratamiento, dejando ese aspecto radiológico característico en huesos largos y esqueleto axial. ${ }^{1,2}$

La interpretación radiológica es simple si el antecedente de administración de bifosfonatos está presente. Una entidad diferencial son las líneas de Park -Harris, llamadas líneas de detención del crecimiento. Se observan en estudios radiológicos como líneas radiodensas paralelas al cartílago de crecimiento en huesos inmaduros que luego migran hacia la diáfisis. Se relacionó su aparición con detenciones

received

June 8, 2020

accepted

September 11, 2020

published online

May 24, 2020
Address for correspondence Juana María Ross, MD, Lavalle $23487^{\circ} \mathrm{C}$, Mar del Plata, Argentina (e-mail: juanamross@gmail.com).

temporales del crecimiento en contexto de enfermedad crónica, infección grave o alteración nutricional. A

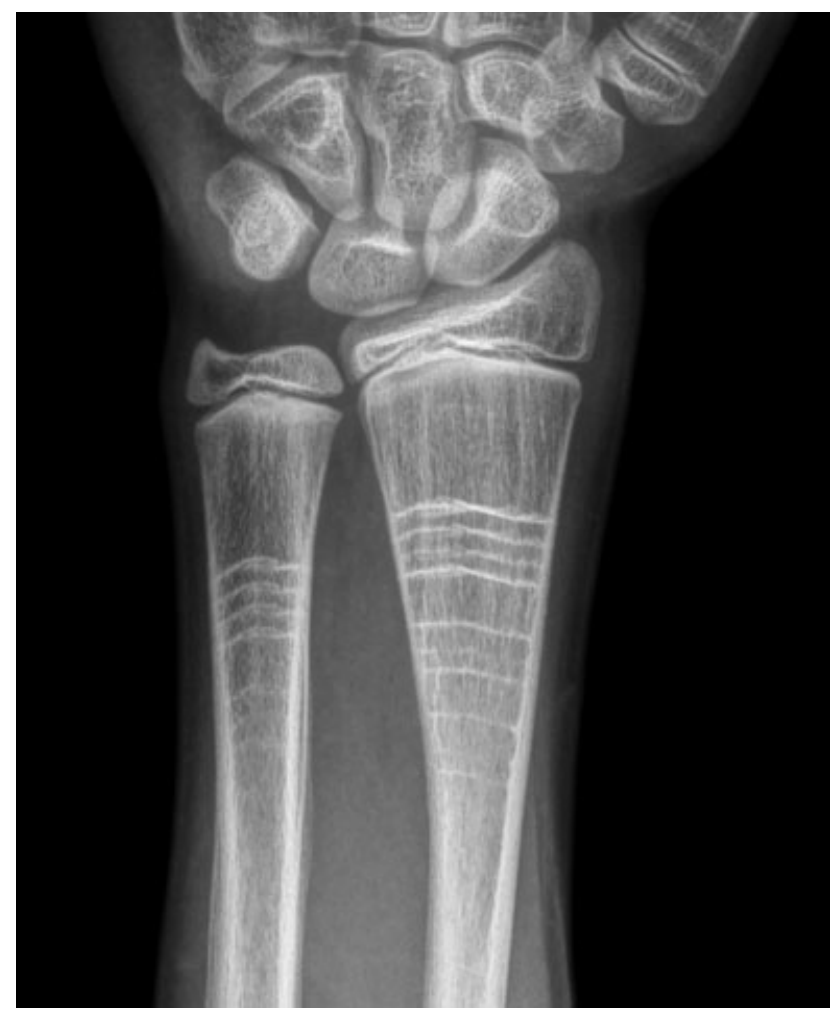

Fig. 1 Radiografía de muñeca de un paciente masculino de 14 años. Había recibido tratamiento con bifosfonatos por antecedente de ostegénesis imperfecta. Nótense las bandas radiodensas paralelas al cartílago de crecimiento desplazadas hacia la diáfisis, constituyendo el signo de las líneas de cebra.
(C) 2020. Asociación Civil Sociedad Argentina de Radiología and Federacion Argentina de Asociaciones de Radiología, Diagnóstico por Imágenes y Terapia Radiante. All rights reserved.
This is an open access article published by Thieme under the terms of the Creative Commons Attribution-NonDerivative-NonCommercial-License, permitting copying and reproduction so long as the original work is given appropriate credit. Contents may not be used for commercial purposes, or adapted, remixed, transformed or built upon. (https://creativecommons.org/ licenses/by-nc-nd/4.0/)
Thieme Revinter Publicações Ltda., Rua do Matoso 170, Rio de Janeiro, RJ, CEP 20270-135, Brazil

$10.1055 / \mathrm{s}-0040-1721342$ ISSN 1852-9992. 
diferencia de las líneas cebra, pueden permanecer en la edad adulta con mayor frecuencia. 2,3

En conclusión, el signo de las líneas de cebra, es un hallazgo radiológico llamativo que refiere a la aparición de bandas lineales densas ubicadas en la zona metafisaria de los huesos. Si bien carece de significación clínica, su presencia puede causar confusión, por lo que debe ser conocido por el médico radiólogo. $\mathrm{Si}$, en un paciente con el esqueleto en crecimiento, conocemos el antecedente terapéutico con bifosfonatos cíclicos, el diagnóstico de estas lineas seria simple. De otra manera, diagnósticos diferenciales deberán ser tenidos en cuenta.

\section{Responsabilidades éticas}

Protección de personas y animales. Los autores declaran que para esta investigación no se han realizado experimentos en seres humanos ni en animales.

Confidencialidad de los datos. Los autores declaran que han seguido los protocolos de su centro de trabajo sobre la publicación de datos de pacientes.
Derecho a la privacidad y consentimiento informado. Los autores declaran que en este artículo no aparecen datos de pacientes.

\section{Conflictos de intereses}

Los autores declaran no presentar ningún conflicto de intereses en relación con el manuscrito presentado. Los autores no recibieron financiación para la realización del presente artículo.

\section{Bibliografía}

1 Al Muderis M, Azzopardi T, Cundy P. Zebra lines of pamidronate therapy in children. J Bone Joint Surg Am. 2007;89(07): 1511-1516

2 Etxebarria-Foronda I, Gorostiola-Vidaurrazaga L. Líneas cebra: Repercusión radiológica de la acción de los bifosfonatos en el esqueleto inmaduro. Rev Osteoporos Metab Miner. 2013;5(01): $39-41$

3 Vázquez I, Masquijo JJ. Líneas de Park-Harris. Rev Argent Radiol. 2014;78(02):120-121 
